\title{
LUMBAR LORDOSIS, PAIN INTENSITY AND TYPE OF WORK IN WOMEN PARTICIPATING IN FITNESS ACTIVITIES
}

\author{
PATRYCJA PROSKURA1, MAŁGORZATA SOBERA² \\ Department of Athletics and Gymnastics, University of Physical Education in Wrocław, Poland \\ Mailing address: Patrycja Proskura, University of Physical Education in Wroclaw, Department of Athletics \\ and Gymnastics, 35 I.J. Paderewskiego Avenue, 51-617 Wrocław, \\ e-mail: patrycjaproskura@wp.eu, tel.: +48 713473372
}

\begin{abstract}
Introduction. The aim of this study was to examine women participating in fitness activities regarding their level of disability in daily activities and lumbar lordosis. Material and methods. Data were collected from 68 females between the ages of 2570 participating in fitness exercises. The Oswestry Disability Index was applied to measure the level of disability due to the low back pain in everyday life. The angle of lumbar lordosis was measured using a Saunders' digital inclinometer. Results. The results of the study confirmed the existence of problems related to low back pain in people performing sedentary work. There were no correlations between lumbar lordosis angle and the level of disability in daily activities of the groups. The low back pain increases especially among people performing sedentary work. Conclusions. The results of this study suggest that work in a sitting position is not associated with a decrease in the angle of lordosis in relation to another work than in a sitting position. Sitting work can be an indirect cause of back pain and slight disability in everyday life by weakening postural muscles.
\end{abstract}

Key words: back pain, sedentary work, The Oswestry Disability Index

\section{Introduction}

Nowadays, low back pain is a major problem and is becoming more and more common among young people. It may have impact on people's functional level in everyday life, influencing its quality [1].

People more likely to suffer from low back pain live sedentary lifestyles and work in a sitting position [2, 3, 4]. Physical activity is one of the most recommended methods to manage and prevent low back pain, something which has been confirmed by many studies $[5,6,7,8,9]$.

People performing sedentary work are often aware that one of the solutions to low back pain is physical exercise. They frequently decide to take up group exercise fitness classes offered by many fitness clubs [10]. Nonetheless, such classes do not address the individual needs of participants. The assumption is that fitness classes named, e.g. 'healthy spine', are dedicated to healthy people and aimed at preventing low back pain by having participants do all types of core strengthening and stretching exercises. But in fact, people who choose this type of exercise already suffer from back pain often resulting from abnormal spinal curves.

The correct shape of the spine in the frontal plane should appear to be a vertically straight line. Viewed from the lateral plane, the spine has a S-shape curve comprised of the cervical and lumbar lordosis and thoracic kyphosis [11]. The biomechanical perspective on spinal curvature emphasizes its key function in absorbing loads in daily activities. The shape of lumbar lordosis has the most significant influence on force distribution within the lower segment of the spine. The shape of this part depends on individual predispositions, genetic features, size of vertebral bodies, intervertebral discs, body mass, sacrum position, age and abdominal muscles $[12,13,14]$.

The values of lumbar lordosis considered normal are ambiguous and the range of norms is vast. This is related to the type of the tampon method used, for example using side radiographs of the lumbar spine. Studies of Lord at al. [15] have shown that lumbar lordotic angle data collected from a group of 109 participants (including 70 males and 39 females between the ages of 2l-83) taken in the standing position were on average $49 \pm 15^{\circ}$ and in the sitting position $34 \pm 15^{\circ}$. However, tests carried out with the use of an inclinometer use the following standards: $30^{\circ}-40^{\circ}$ lumbar lordosis [16]. These standards can be used for different age groups. In studies conducted on 3869 people aged 7-35 differences in the size of lumbar lordosis between the youngest and the oldest group did not exceed $2^{\circ}$ [17]. Some authors $[14,18]$ have demonstrated that both too large and too small an angle of lumbar lordosis results in low back pain. The most common lumbar pathologies are: deepened lumbar curvature (lumbar hyperlordosis), lessened curvature or flattening of the low back (hypolordosis or dyslordosis) and abnormal curving of the spine to the side in the frontal and transverse plane (scoliosis) [19].

It seems reasonable to verify if low back pain depends on the value of lumbar lordosis angle with respect to the type of work performed in the most frequently taken position.

The aim of this study was to examine the relationship between angular values of the lumbar lordosis, pain intensity, the type of work performed and level of physical activity in everyday life.

\section{Material and methods}

The research group was comprised of 75 females between the ages of 25-70 who were starting to participate in fitness twice a week ( 2 times per 1 hour) since one month (Fig. 1). At that time, these women participated only in these fitness classes. The majority of the test participants perform sedentary work ( $\mathrm{n}$ = 57), another females who declared the different kind of work 


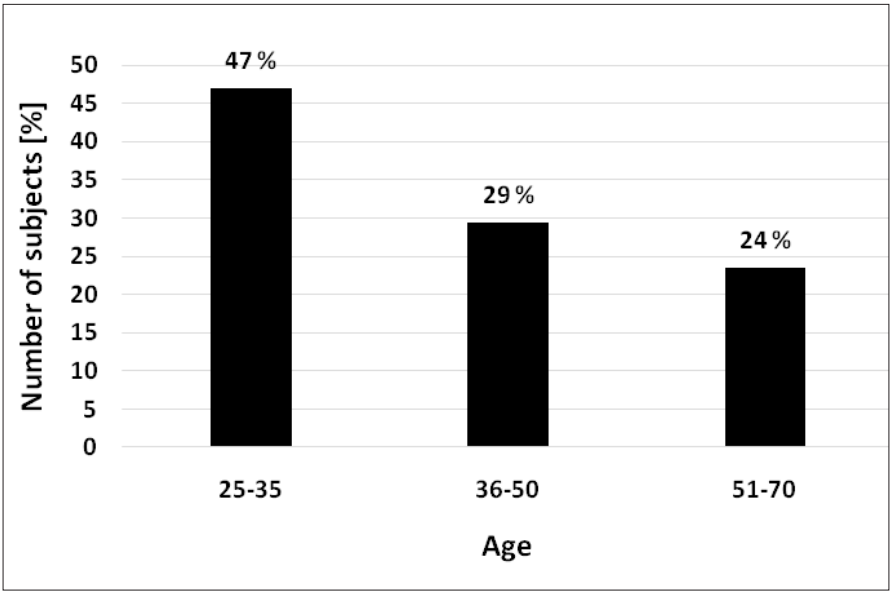

Figure 1. Characteristic of the subjects tested with respect to age

not sedentary but physical work $(n=9)$. There were pensioners in the group as well $(n=9)$.

The level of disability due to low back pain in everyday life was measured with the Oswestry Disability Index [20, 21, 22]. The questionnaire is based on ten questions referring to the following parameters: pain intensity, personal care, lifting, walking, sitting, standing, sleeping, social life, professional life, housework and travelling. A respondent checks one box for each parameter for the statement which best applies to their condition. Each answer is scored from 0 to 5 . The total possible score from all ten sections ranges from 0 to 50 . The best scores are close to 0 and reflect minimal disability with no limitations in performing daily activities. The outcome of 50 points $(100 \%)$ is the worst result reflecting serious limitations in performance in everyday life [20].

The survey results were interpreted according to Fairbank [20] in which the points are converted to percentage:

- 0\%-20\% - minimum disability,

- $21 \%-40 \%$ - moderate disability,

- $41 \%-60 \%$ - severe disability,

- 61\%-80\% - crippled,

- 81\%-100\% - bed-bound.

Associations between pain intensity and daily activities was checked in a group of women working in a sitting position, therefore those who showed zero disability were excluded.

Values of lumbar lordosis were measured using a Saunders digital inclinometer [21]. Prior to the test the following anthropometric points were marked on each subject's body: the cervicothoracic junction (C7-Thl), thoracolumbar junctions (Thl2-L1) and lumbosacral junction (L5-S1). A special marker was used to mark x-points between certain spinous processes. Measurements were taken in the free standing position in bare feet. Feet were placed at the iliac width, parallel to each other. The upper limbs were lowered alongside the torso in the free position. Measurements were taken in accordance to the digital inclinometer's operating instructions [21]. In order to determine the inclination angle of the sacrum, the inclinometer was calibrated in the horizontal position and applied to the lumbosacral junction (L5-S1). The inclinometer was set to zero at the lumbosacral junction (L5-S1). The readout of values was taken at the thoracolumbar junction (Th12-L1). Each the readout was performed 3 times. Further analysis involved taking the mean value of the three readouts which differed maximally in the range of $1-2^{\circ}$. The results for the values of lumbar lordosis angle were compared to the norms of the American Medical Association [16].

\section{Statistical analysis}

The distribution of the data set was screened for normality using the Shapiro-Wilk test, including the following factors: type of work and level of disability in everyday life. The distribution of lumbar lordosis met the assumptions of normality, hence one-way ANOVA was used. The distribution of levels of disability in everyday life did not meet the assumptions of normality, thus the differences in disability in reference to type of work were analyzed with the Kruskal-Wallis ANOVA test.

Relationships between the reported pain intensity, disability in everyday activities were established based on Spearman's rank correlation coefficient. They were tested among people working in a sitting position who were found to be minimal disability or moderate disability. The correlation coefficient ' $r$ ' takes a range of values from $-1 \leq \mathrm{r} \leq 1$ according to Stanisz [23]:

$\mathrm{r}=0$ no relationship,

$0<\mathrm{r}<0.1$ very weak relationship,

$0.1 \leq \mathrm{r}<0.3$ weak relationship,

$0.3 \leq \mathrm{r}<0.5$ moderate relationship,

$0.5 \leq \mathrm{r}<0.7$ strong relationship,

$0.7 \leq \mathrm{r}<0.9$ very strong relationship,

$0.9 \leq \mathrm{r}<1.0$ almost perfect relationship.

The results were considered significant at $\alpha=0.05$. Data were processed with the Statistica 13.1 software package.

\section{Ethical approval}

The research related to human use has been complied with all the relevant national regulations and institutional policies has followed the tenets of the Declaration of Helsinki and has been approved by the Bioethical Committee of the University School of Physical Education in Wrocław (approval No. 29/2018).

\section{Results}

The lumbar lordosis and level of disability in everyday life vs type of work

The variables analyzed were presented as percentages. The norm of the lumbar lordotic angle accepted by the American Medical Association [16] is between $30^{\circ}$ and $40^{\circ}$. With this in mind, the curvature of lumbar lordosis was correct in $47 \%$ of the subjects tested. There were no statistically significant differences between the angular values of lumbar lordosis and pain intensity. Significant differences were found between the angular values of lumbar lordosis and the type of work performed as observed at $\mathrm{p}=0.03$ (Fig. 2). Subjects performing physical work were characterized by slightly lower angular values of lumbar lordosis in comparison to those performing sedentary work. Pensioners obtained the lowest angular values of lumbar lordosis in comparison to the professionally active group (Fig. 2). The results regarding the general level of disability in everyday life with respect to low back pain in the women tested demonstrated that the majority $(68 \%)$ reported a minimum level of disability. Only 4\% surveyed as severe disability while performing daily activities. However, there were no statistically significant differences between level of disability in everyday life and the type of work, which was confirmed by a high $\mathrm{p}=0.45$ (Fig. 3). 
$F(2,72)=3.81, p=0.03$

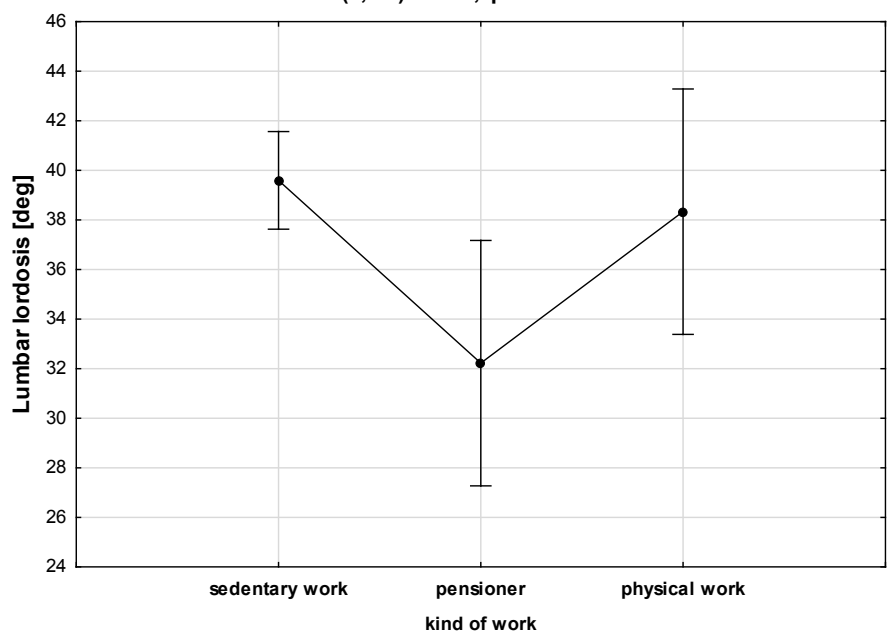

Figure 2. Distribution of angular values of lumbar lordosis $(\mathrm{N}=75)$ with respect to the kind of work

\section{Pain intensity in everyday activities in people who have sedentary work}

This was a cross-sectional survey so we could claim about associations of the back pain and the lumbar lordosis. The association between the reported pain intensity and the disability in everyday activities has been checked among people who work in sitting position $(n=57)$ because the largest number of women among the respondents working in a sitting position and a sedentary lifestyle as one of the reasons for the appearance of back pain.

There were two significant positive associations between the variables of women with minimal disability. There was a moderate association $(\mathrm{r}=0.48)$ between pain intensity and level of pain while sitting (Tab. 1). Another moderate significant association $(r=0.39)$ was found between the level of pain while standing and level of pain while travelling (Tab. 1).

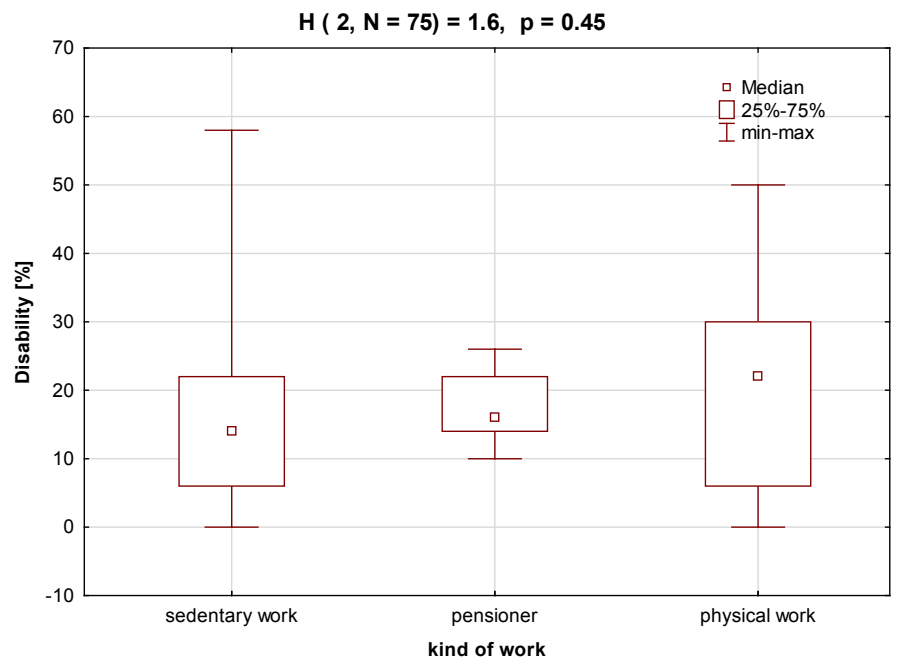

Figure 3. The distribution of levels of disability in everyday life $(\mathrm{N}=75)$ with respect to the kind of work

The results also demonstrated two significant strong associations between the variables of women with moderate disability. There was negative association $(\mathrm{r}=-0.56)$ between level of pain while personal care and level of pain while standing (Tab. 2). Another strong association $(\mathrm{r}=0.57)$ was found between level of pain while standing and level of pain while walking (Tab. 2).

There is no significantly association between lumbar lordosis and other variables both women with minimal and moderate disability in everyday life.

There were only two women classified as a severe disability so it was no possible to find any association between described variables.

There were seven women who classified as a 'zero' disability, therefore there was no reason to present associations among them.

Table 1. Correlations between the angle of lumbar lordosis and the level of perceived back pain in everyday activities among people who have sedentary work with minimal disability $(\mathrm{n}=34)$

\begin{tabular}{|c|c|c|c|c|c|c|c|c|c|c|}
\hline \multirow{2}{*}{ Variable } & \multicolumn{10}{|c|}{ Variable } \\
\hline & Lumbar lordosis & Pain intensity & Personal care & Lifting & Walking & Sitting & Standing & Sleeping & Social life & Travelling \\
\hline Lumbar lordosis & --- & & & & & & & & & \\
\hline Pain intensity & 0.03 & --- & & & & & & & & \\
\hline Personal care & -0.07 & 0.09 & --- & & & & & & & \\
\hline Lifting & 0.25 & 0.19 & -0.03 & --- & & & & & & \\
\hline Walking & -0.09 & -0.07 & 0.21 & 0.07 & -- & & & & & \\
\hline Sitting & 0.15 & $0.48^{*}$ & 0.11 & 0.29 & 0.07 & -- & & & & \\
\hline Standing & 0.17 & 0.12 & -0.03 & 0.02 & 0.06 & -0.04 & -- & & & \\
\hline Sleeping & 0.02 & 0.18 & 0.07 & -0.01 & 0.04 & 0.11 & 0.16 & -- & & \\
\hline Social life & 0.06 & -0.05 & -0.08 & 0.23 & -0.04 & -0.24 & 0.28 & -0.15 & -- & \\
\hline Travelling & -0.06 & 0.20 & 0.21 & 0.15 & -0.01 & 0.21 & $0.39 *$ & 0.05 & -0.01 & -- \\
\hline
\end{tabular}

* $-\mathrm{p} \leq 0.05$ - correlation statistically significant. 
Table 2. Correlations between the angle of lumbar lordosis and the level of perceived back pain in everyday activities among people who have sedentary work with moderate disability $(\mathrm{n}=14)$.

\begin{tabular}{|c|c|c|c|c|c|c|c|c|c|c|}
\hline \multirow{2}{*}{ Variable } & \multicolumn{10}{|c|}{ Variable } \\
\hline & Lumbar lordosis & Pain intensity & Personal care & Lifting & Walking & Sitting & Standing & Sleeping & Social life & Travelling \\
\hline Lumbar lordosis & --- & & & & & & & & & \\
\hline Pain intensity & 0.33 & -- & & & & & & & & \\
\hline Personal care & -0.19 & 0.07 & --- & & & & & & & \\
\hline Lifting & 0.06 & -0.45 & -0.08 & -- & & & & & & \\
\hline Walking & -0.01 & 0.21 & -0.38 & -0.30 & --- & & & & & \\
\hline Sitting & -0.39 & -0.26 & -0.18 & -0.20 & 0.40 & -- & & & & \\
\hline Standing & 0.02 & 0.11 & $-0.56^{*}$ & -0.12 & $0.57^{*}$ & 0.27 & -- & & & \\
\hline Sleeping & -0.28 & 0.02 & -0.48 & -0.34 & 0.06 & 0.10 & 0.22 & -- & & \\
\hline Social life & -0.11 & 0.31 & -0.34 & -0.32 & -0.05 & 0.01 & 0.29 & 0.44 & -- & \\
\hline Travelling & -0.03 & -0.03 & 0.51 & -0.15 & -0.17 & 0.05 & -0.36 & -0.29 & 0.18 & --- \\
\hline
\end{tabular}

${ }^{*}-\mathrm{p} \leq 0.05$ - correlation statistically significant.

\section{Discussion}

Pain syndromes cause limitations in professional, social and family life and have negative impact on the quality of life. Daily activities become more difficult to perform (walking, standing, sitting) and social and professional activity drops $[1,18]$ which is supported by the results presented above. It should be emphasized that in our own research there were no statistically significant differences observed between disability in everyday life and type of work, which was shown in a high $\mathrm{p}=0.45$. Associations between work factors and self-reported low back pain during the previous 12 months that interfered with usual activities were examined among 4493 standing workers and 3237 sitting workers. This study has nonetheless demonstrated that not to be able to sit at will at work is a risk factor for low back pain among those who stand at work and that different physical and psychological risk factors were associated with low back pain among sitting and standing workers [24].

The results obtained for the test group revealed that in almost half of the studied women the lumbar lordosis were in the normal range $\left(30^{\circ}-40^{\circ}\right)$ in reference to the norms for the measurement method. In contrast, $44 \%$ of subjects had hyperlordosis. From the results, it is clear that differences in the lumbar lordosis were significant, but only between women performing sedentary and physical work and the pensioners (Fig. 2). The results showed minor differences in the angular values of lumbar lordosis between people who work in sitting position and people who have physical work. This is consistent with what has been found in previous studies carried out on 508 subjects between the ages of 20-65, which did not confirm the influence of lifestyle on the angular values of lumbar lordosis [25]. However, research carried out by Chromik et al. [26] on 48 athletes and 38 non-training college students confirmed that the angular values of lumbar lordosis were higher in non-training students $\left(31.36^{\circ}\right)$ against futsal players $\left(21.36^{\circ}\right)$ and soccer players $\left(18.31^{\circ}\right)$. The lifestyles of retirees frequently change when they stop working which may be the reason for the significant changes in the angular values of lumbar lordosis. The influence of age on those type of changes should also be considered. However, research carried out by Harvey et al. On 349698 subjects older than 60 confirmed that stopping work and retirement increase the amount of time spent in the sitting position [27]. Our own studies have confirmed the findings that a sedentary lifestyle is linked to problems with back pain. Women who work in sitting position with minimal disability showed an average relationship between the intensity of general pain with pain while sitting. The intensity of back pain is mainly associated with the sensation of pain in a sitting position which in this group is the position taken at work. In other daily activities described no significant correlation was found with pain intensity (Tab. 1). This means that sitting for several hours in women who have sedentary work is the main cause of the declared intensity of pain. This relationship supports the notion that low back pain in people leading a sedentary lifestyle needs to be examined. In their research conducted on 648 white-collar workers Spyropoulos et al. [2] established the occurrence of low back pain in $62 \%$ of respondents. Kaczor et al. [28] have investigated 100 subjects (including 57 white-collar workers and 43 drivers) confirming low back pain in $57 \%$ of respondents working in a sitting position. Sitting in a static position for a prolonged period of time can result in injuries to the musculoskeletal system [29]. When sitting for an extended period the human spine and joints both knee and hip are flexed. The degree of flexion, however, depends on many factors. In the sitting position the pelvis tilts backward in the sagittal plane. This decreases the angular values of lumbar lordosis and increases the load on the posterior components of the passive subsystem [30]. Additionally, the passive sitting position referred to as kyphotic is characterized by decreased activity in the lumbosacral muscles and increase in the neck. This provides evidence that extended periods in a sitting position significantly contribute to abnormalities in anterior-posterior spinal curvature. People living a sedentary lifestyle also suffer from hyperlordosis or hypolordosis although it may appear that they are prone to flattening of lumbar lordosis owing to being in the sitting position long term. Reviewing the literature indicates that both big and small lordotic angles may cause low back pain $[14,18]$. Regarding lumbar flattening the load on the surface of the joints, vertebral bodies in particular, is unevenly distributed causing an increased load on the ventral surface of these vertebrae. Simultaneously, pressure decreases on the vertebral bodies from the dorsal side. This leads to posterior intervertebral discs protruding into the spinal canal causing pain in the area [1]. In 
the case of the deepening of lumbar lordosis the pathomechanism of low back pain differs. The load on the vertebral arches increases decreasing the compression load on the intervertebral discs [1] especially from the ventral side. Increased pressure on the posterior structure of the lumbar vertebrae causes compression of the spinal nerve root and pain in the area [1]. Such a pathomechanism is observed in obese people, women in the third trimester of pregnancy $[31,32,33]$ and people with too much tension (shortening) in the lumbar erector spinae [34].

Among people who have sedentary work with minimal disability was another moderate correlation - between level of pain while standing and level of pain while travelling $(r=0.39)$. This may be related to traveling by public transport when often due to lack of seating and crowd, people are forced to stand often in an uncomfortable position. While standing the lumbar spine is in an incorrect position with either too large or small anterior pelvic tilt. The increase in the anterior pelvic tilt angle increases lumbar lordosis. Abnormal pelvic tilt in the frontal and transverse planes is the cause of scoliosis and can be responsible for pain [1]. Some authors [35, 36] have also suggested that being in a standing position for an extended period of time may result in low back pain. Locks et al. [35] in their research on 667 bluecollar workers have reported that being in the standing position for an extended period of time may have influence on hip pain. Hip pain leads to flexed hip and knee muscles which in turn can create habitual posture that puts the pelvis into an anterior tilt. This results in the flattening of lumbar lordosis, and later in pain. Studies of Yildirim et al. [36] carried out on 111 workers of the packaging industry have confirmed that low back pain was observed and was related to incorrect standing and sitting positions.

Another described correlations were strong between. There were among people who have sedentary work with moderate disability. The first correlation was between the pain felt while standing and the pain experienced while walking $(\mathrm{r}=0.57)$. As already discussed above, incorrect adjustment of the lumbar spine may result in the appearance of pain. In contrast, the pain in the spine felt while walking may also be associated with abnormal postural habits (hyperlordosis). Tests carried out on 22 people with chronic back pain showed that during walking the lumbar erector spinae is excessively active [37]. Second strong but significant correlation among people who work in sitting position with moderate disability was between pain felt personal care and the pain experienced while standing $(\mathrm{r}=-0.56)$. This seems understandable due to the fact that most care activities women with great discomfort in the spine perform in a sitting position (e.g. makeup, styling the hair, dressing) in which they feel less pain than when standing as evidenced by a strong positive correlation between standing and walking. Most likely, the reason for this condition is weakness in the abdominal muscles as well as overweight which in a standing position may be the cause of hyperlordosis and too much load on the lumbar spine. This could be associated with the appearance of back pain [31, 33].

\section{Conclusions}

The results of this study suggest that work in a sitting position is not associated with a decrease in the angle of lordosis in relation to another work than in a sitting position. Sitting work can be an indirect cause of back pain and slight disability in everyday life by weakening postural muscles. Further studies should investigate what is a safe angle for the lumbar lordosis in prevention of back pain and determine how it should change in order to avoid low back pain. Simultaneously, there is a strong relationship between back pain and everyday activities and performance. However, it is not related to the type of work clearly (if the division adopted in this work is accepted).

\section{Literature}

1. Stodolny J. (2004). Choroba przeciążeniowa kręgosłupa. Kielce: ZL Natura. [in Polish]

2. Spyropoulos P., Papathanasiou G., Georgoudis G., Chronopoulos E., Koutis H., Koumoutsou F. (2007). Prevalence of low back pain in Greek public office workers. Pain Physician 10(5), 651-659.

3. Damanhuri Z., Zulkifli A., Lau A.C.T., Zainuddin H. (2014). Low back pain among office workers in a public university in Malaysia. International Journal of Public Health and Clinical Sciences 1(1), 99-108.

4. Smuka I. (2018) Youth physical activity as an out-of-class occupation. Polish Journal of Sport and Tourism 25(3), $42-$ 45. DOI: 10.2478/pjst-2018-0019.

5. Rainville J., Hartigan C., Martinez E., Limke J., Jouve C., Finno M. (2004). Exercise as a treatment for chronic low back pain. Spine 4(1), 106-115. DOI: 10.1016/s15299430(03)00174-8.

6. Gladwell V., Head S., Hagger M., Beneke R. (2006). Does a Program of Pilates Improve Chronic Non-Specific Low Back Pain. Journal of Sport Rehabilitation 15, 338-350. DOI: 10.1123/jsr.15.4.338.

7. Oliveira C.B., Franco M.R., Maher C.G., Tiedemann A., Silva F.G., Damato T.M. et al. (2018). The efficacy of a multimodal physical activity intervention with supervised exercises, health coaching and an activity monitor on physical levels of patients with chronic, nonspecific low back pain (Physical Activity for Back Pain (PAyBACK) trial: study protocol for a randomised controlled trial. Trials 15;19(1), 40. DOI: 10.1186/s13063-017-2436-z.

8. Hayden J.A., Wilson M.N., Stewart S., Cartwright J.L., Smith A.O., Riley R.D., et al. (2019). Exercise treatment effect modifiers in persistent low back pain: an individual participant data meta-analysis of 3514 participants from 27 randomised controlled trials. British Journal of Sports Medicine 28. Retrived September 1, 2019 from https://bjsm.bmj.com/content/early/2019/11/27/bjsports-2019-101205. DOI: 10.1136/ bjsports-2019-101205.

9. Shariat A., Alizadeh R., Moradi V., Afsharnia E., Hakakzadeh A., Ansari N.N. et al. (2019). The impact of modified exercise and relaxation therapy on chronic low back pain in office workers: a randomized clinical trial. Journal of Exercise Rehabilitation 15(5), 703-708. DOI: 10.12965/ jer.1938490.245

10. Aboagye E., Hagberg J., Axén I., Kwak L., Lohela-Karlsson M., Skillgate E. et al. (2017). Individual preferences for physical exercise as secondary prevention for non-specific low back pain: A discrete choice experiment. PLoS One 15; 12(12): e0187709. DOI: 10.1371/journal.pone.0187709.

11. Trew M., Everett T. (2005). Human movement. An introductory text. Edinburgh: Elsevier Churchill Livingstone.

12. Scannell J.P., McGill S.M. (2003). Lumbar Posture - Should It, and Can It, Be Modified? A Study of Passive Tissue Stiffness and Lumbar Position During Activities of Daily Living. Physical Therapy 83(10), 907-917.

13. Whitcome K.K., Shapiro L.J., Lieberman D.E. (2007). Fetal load and the evolution of lumbar lordosis in bipedal homi- 
nins. Nature 13; 450(7172), 1075-1078. DOI: 10.1038/nature06342.

14. Chun S.W., Lim C.Y., Kim K., Hwang J., Chung S.G. (2017). The relationships between low back pain and lumbar lordosis: a systematic review and meta-analysis. Spine 17(8), 1180-1191. DOI: 10.1016/j.spinee.2017.04.034.

15. Lord M.J., Small J.M., Dinsay J.M., Watkins R.G. (1997). Lumbar lordosis. Effects of Sitting and Standing. Spine 22(21), 2571-2574. DOI: 10.1097/00007632-19971101000020.

16. Andersson G.B.J., Cocchiarella L. (2004) American Medical Association. Guides to the Evaluation of Permanent Impairments. $5^{\text {th }}$ ed. Chicago: American Medical Association.

17. Zeyland-Malawka E. (2003). Results of measurement of spinal curvatures as a reference system for body posture examination. Physiotherapy 11(3), 5-12.

18. McGill S. (2016). Low back disorders: Evidence-Based Prevention and Rehabilitation $3^{\text {rd }}$ edition. Champaign: Human Kinetics.

19. Roussouly P., Gollogly S., Berthonnaud E., Dimnet J. (2005). Classification of the normal variation in the sagittal alignment of the human lumbar spine and pelvis in the standing position. Spine 30(3), 346-353. DOI: 10.1097/01. brs.0000152379.54463.65.

20. Fairbank J.C.T., Pynsent P.B. (2000). The Oswestry Disability Index. Spine 25(22), 2940-2953. DOI: 10.1097/00007632200011150-00017.

21. Saunders Digital Inclinometer. Operating Instructions, Technomex Sp. z O.O, Gliwice. [in Polish]

22. Yates M., Shastri-Hurst N. (2017). The Oswestry Disability Index. Occuptional Medicine 67(3), 241-242. DOI: 10.1093/ occmed/kqw051.

23. Stanisz A. (2006). Statistics course. Kraków: StatSoft Polska. [in Polish]

24. Tissot F., Messing K., Stock S. (2009). Studying the relationship between low back pain and working postures among those who stand and those who sit most of the working day. Ergonomics 52(11), 1402-1418. DOI: 10.1080/00140130903141204.

25. Arab A.M., Nourbakhsh M.R. (2014). Hamstring muscle length and lumbar lordosis in subjects with different lifestyle and work setting: comparison between individuals with and without chronic low back pain. Journal of Back and Musculoskeletal Rehabilitation 27(1), 63-70. DOI: 10.3233/ BMR-130420.

26.Chromik K., Burdukiewicz A., Pietraszewska J., Stachoń A., Wolański P., Goliński D. (2017). Characteristics of anteroposterior curvatures of the spine in soccer and futsal players. Human Movement 18(4), 49-54. DOI: https://doi. org/10.1515/humo-2017-0039.

27. Harvey J.A., Chastin S.F., Skelton D.A. (2015). How Sedentary are Older People? A Systematic Review of the Amount of Sedentary Behavior. Journal of Aging and Physical Activity 23(3), 471-87. DOI: 10.1123/japa.2014-0164.

28. Kaczor S., Bac A., Brewczyńska P., Woźniacka R., Golec E. (2011). The occurrence of low back pain and motor habits in sedentary people [in Polish]. Advances in rehabilitation 3, 19-28. DOI 10.2478/rehab-2013-0011.

29. Mork P.J., Westgaard R.H. (2009). Back posture and low back muscle activity in female computer workers: A field study. Clinical Biomechanics (Bristol, Avon) 24, 169-175. DOI: 10.1016/j.clinbiomech.2008.11.001.

30. De Carvalho D.E., Soave D., Ross K., Callaghan J.P. (2010) Lumbar spine and pelvic posture between standing and sitting: a radiologic investigation including reliability and repeatability of the lumbar lordosismeasure. Journal of Manipulative and Physiological Therapeutics 33(1), 48-55. DOI: 10.1016/j.jmpt.2009.11.008.

31. Orvieto R., Rand N., Lev B., Wiener M., Nehama H. (1994). Low back pain and BMI. Military Medicine 159(1), 37-38.

32. Sipko T., Grygier D., Barczyk K., Eliasz G. (2010). The Occurrence of Strain Symptoms in the Lumbo sacral Region and Pelvis During Pregnancy and After Child birth. Journal of Manipulative and Physiological Therapeutics 33(5), 370377. DOI: 10.1016/j.jmpt.2010.05.006.

33. Dario A.B., Ferreira M.L., Refshauge K.M., Lima T.S., Ordoñana J.R., Ferreira P.H. (2015). The relationship between obesity, low back pain, and lumbar disc degeneration when genetics and the environment are considered: a systematic review of twin studies. Spine 15(5), 1106-1117. DOI: 10.1016/j.spinee.2015.02.001.

34. Vignaduzzo S.E., Castellano P.M., Kaufman T.S. (2010). Development and validation of a dissolution test for meloxicam and pridinolmesylate from combined tablet formulation. Indian Journal Pharmaceutical Sciences 72(2), 197-203. DOI: 10.4103/0250-474X.65033.

35. Locks F., Gupta N., Hallman D., BirkJørgensen M., Oliveira A.B., Holtermann A. (2018). Association between objectively measured static standing and low back pain - a cross-sectional study among blue-collar workers. Ergonomics 61(9), 1196-1207. DOI: 10.1080/00140139.2018.1455900.

36. Yildirim Y., Gunay S., Karadibak D. (2014). Identifying factors associated with low back pain among employees working at a package producing industry. Journal of Back and Musculoskeletal Rehabilitation 27(1), 25-32. DOI: 10.3233/ BMR-130415.

37. Lamoth C., Meijer O.G., Daffertsthofer A., Wuisman P.I.J.M., Beek P.J. (2006). Effects of chronic low back pain on trunk coordination and back muscle activity during walking: Changes in motor control. European Spine Journal 15(1), 23-40. DOI: 10.1007/s00586-004-0825-y.

Submitted: September 7, 2019

Accepted: December 20, 2019 